\title{
Videotex as a Tool for Health Promotion
}

By Michel Bourque, Ph.D., Robert Perreault, M.D.

Abstract

As one of the major components of health promotion, education is more and
more becoming the focus of health planners. Based on the efficiency criteri tion strategies, the exploration of the new computer-assisted media to pursue healt promotion objectives offers challenge. also raises important pedagogical issues based on the experience of the Tele Health project. Using the Canadia videotex technology, Tele-Health produces and makes accessible numerous in teractive programs for both public/patien tion.

Introduction As one of the major components of
health promotion, education is more and more becoming the focus of health plan-
ners. The central reason for all this scrutiny lies with the obstacles that have been stressed in the health education literature regarding both its impact and its efficacy. Furthermore, many of the demonstration and evaluation studies
that have brought positive results have that have brought positive results have
been labor intensive making their generalization doubtful in an era of high economic constraints. Nevertheless, the work done in the last decade relative promote healthy lifestyles and competen help-seeking has validated a number criteria for the exploration of alternative educational technologies.

According to Green (1980) who conducted a thorough survey of the literature on the subject, a number of pedagogical tive in the transmissio of tion: the communication of the materia should occur in an interactive environ ment; the acquisition of behavioral skills
should be favored; traditional pedagogical

Michel Bourque is the director of th Research Institute of Montreal.

Robert Perreault is from the Communi Health Department, Montreal General
Hospital. criteria should be respected; the education process should be integrated in the
user's daily life; it should afford continuity with existing resources of this environment; finally, the potential solutions should be cost-efficient.

As can be seen, these observations su gest that the material should be adapte a way that provides immediate feedback. The selected teaching vehicle has to provide for the teaching of behavioral skil (Wright, 1981) as well as being able convey information using the highest should be integrated in the process environment so as to take place at moments and places of highest spontaneous motivation. This later item is specially important to subjects such as health behavior since the motivation to perception and problem-solving skills. individual constriants has been shown to have very limited impact. Finally, health education systems need to be easily integrated in the already existing delivery and health promotion organizations. most if not all the above-mentioned criteria, computer-assisted interactive ing alternative to one-to-on a promiseducator-patient interaction. While the field has been under study for nearly two decades (Slock and Slock, 1972), it is only recently that the available technologies gave made it possible to overcome its two tention span stemming from unappeling text displays and high cost of individual work stations and networks. The maturation of microcomputer technology has
brought the cost down and the developbrought the cost down and the development of the high resolution color display solving the problems related to appeal and user friendliness in a cost-effective fashion.

The Tele-Health Project

Over the past three years, the present evaluating computer-assisted interactive teaching as a tool for public health education as well as for continuing medical education. Using the Canadian Telidon videotex technology, they are building a
health information databank known as
Tele-Health (Perreault and Bourque, now comprises fifteen th bank (Table now comprises fifteen programs available
to the general public both in private homes and on an experimental specialwaiting rooms of health clinics, physian's offices and public places such pharmacies. These programs' were
selected on the basis of public health TABLE

Tele-Health: Public health databank
themes
- Risk factors
: Food and health
Acohol
: Smoking
Coping with stress
Adolescence and adaptation
- How to select health care services
: Childhood infectious diseases
Vaccination
: Insomnia
Depressive states
Headaches
Cold and flus
- Digestion
Cardiovascular problems

iterature and nationally identified public ealth objectives

In parallel to the public health project,
Tele-Health is developing a professional databank with the goal of providing both ntinuing medical education and informational support to clinical practice. TABLE/II

Tele-Health: Professional databank themes

Informational support to medical Objective criteria protocols for psycho-social problems - Medication guide - Drug int

Continuing medical education: - Selected papers from the medical

Essential bibliographies in health (edited by a panel of experts)

VOLUME 13, NUMBER 2, 198 developed. The professional databank is also designed as a participatory
building process under peer review.

Pedagogical issues

On the basis of this experience, it becomes interesting to attempt to narrow the mediatization process of health. related material for the general public. There are of course many such models for traditional health education. (Green et al, 1980; Green, 1979; Hulka et al, 1975).
Two factors motivate a new attempt Two factors motivate a new attempt
(Bourque and Perreault, 1983). They are based on the fact that the telematic approach introduces new elements into the traditional equation such as direct and immediate access to information and easy
tailoring of information to individual tailoring of information to individu
needs through computer intelligence. The first factor relates to the reinforc ment of the motivation required for challenge to the assumption that formalized presentation of a topic represents a preliminary and essention
any education process.

Reinforcement of initial motivation It has long been recognized in the health information can be made available by many media saturation approaches but
that behavioral change based on this information is only possible if people can chieve the motivation objective, traditional approaches to health education have had to overly expose people to prob-
lems and their solutions with the recognized drawback that the overinformation required to achieve an source of anxiety.

With interactive media, it becomes possible to use the impetus of an invehicle to lead him to a desired sensitization process which can in turn be formulated according to the specific needs and interest of the person. Health infor-
mation then becomes accessible through mation then becomes accessible through
a myriad of entry points. A program a myriad of entry points. A program
focusing on dietary habits, for instance, could be entered through a meal-planning guide, an indigestion-management prother entry point representative of the in terests of target population sub-group habit information but only after the initial interaction has reinforced each indicomparison, traditional approaches mation to the target population forcin osing subjects through lack of motivation raising anxiety through overexposition. The alternatives, all quite costly, would be to devise many programs and to thiply access procedure to various sub-

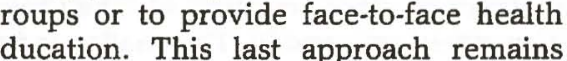
one of the more potent tools available but sually has to be limited to high risk groups due to cost.

Formalization

The second change that is being introduced in health education with the concerns the order of presentastruction various components involved in the education process. It has traditionally been necessary to transmit health-relate information in a formal quasi-academic structure before suggesting the applica. tion of this information to a specific prohis structured approach becomes unnecessary as the information bank can be accessed from many entry points and the interactive nature of the process makes it possible to let the computer lead the use the ing the material. This feature turn solving tool that can be immediately applied to whatever problem or preoccupation motivates contact with the system. The initial usefulness of the experience herefore, provides a strong reinforce-

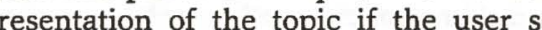
(esires.

People not interested in knowledge acquisition who would normally drop out of health education programs can use th cot that even for the peoper the computer will model a number of skills conducive to better health managemen hown simulation, modeling, feedback and repetition to be extremely poten Most of these components can be built in the computer interaction.

Discussion
Conceptually, computer-assisted media do appear to avoid many of the obstacles health promotion objectives. Preliminary tends to support this hypothesis. However, in their ongoing effort to keep pace planners must avoid the lure of definin objectives that are subservient to the pitfall is to analyse the way to avoid this in the light of the very reel posjectives they have always had to meet in order to see when and how new tools can do old jobs better or deal with previously unreachable objectives. In the final analysis, and as interactive media gain
maturity, systematic planning in the im maturity, systematic planning in the im
plementation of computer-assisted strategies seems very profitable.

REFERENCES

Bourque, M. and Perreault, R. [1983): A planning guide to computer-assisted health promotion. Proceedings of the puter Applications in Medical Care, Baltimore (in press). Green, L.W., Kreuter, M.W., Deeds, S.G
and Partridge, K.B. (1980): Health ostic approach. The Johns Hopkins University, Mayfield Publ. Col, Bosto Green, L.W. (1979): Educational strattherapeutics and preventive the recent evidence. In Haynes, R.B. Taylor, D.W., Sackett, D.L. (eds), Compliance in Health Care, Johns Hopkins University Press, Baltimore. Hulka, B.S., Kupper, L.L., Cassel, J.C. et tion and outcomes among diabetic patients. J. Commun. Health, 1: 15-27. TreAlister, A., Priska, P., Salonen, J., action for health promotion: illustrations from the North Karelia Project, Perreault, R and Bourque, M. (1983: Tele-Health: an interactive television system for health promotion. Pro-
ceedings of SYSTED 83, Charles Tilquin, ed., Montréal (in press). W.F, and Slack, C.W. (1972) Patient-computer dialogue. New Eng.
J. Med., 236: 1304-1309. Wright, J., Mathieu, M. and McDonough, proaches to the teaching of behavioral therapy. J. Clin. Psychology, 37 326-335. 